\title{
LA NOCIÓN DE “VALOR” COMO OBJETO DE TRANSACCIÓN EN EL MERCADO DE VALORES SEGÚN EL DERECHO CHILENO*
}

[The Notion of "Value" as Transaction Object in The Stock Market under the Chilean Law]

\author{
Alejandro GuZMÁn BRITo** \\ Pontificia Universidad Católica de Valparaíso, Chile \\ José Luis Guerrero BeCAR*** \\ Pontificia Universidad Católica de Valparaíso, Chile
}

\begin{abstract}
RESUMEN
En el derecho chileno se utilizan diversas voces para identificar genéricamente al objeto de transacción en el mercado de valores, tales como: "títulos-valores", "efectos de comercio", "instrumentos financieros", "valores", entre otros, y suele otorgárseles significaciones análogas. Como el objeto de transacción representa diversos tipos de actos, parece razonable establecer una
\end{abstract}

\begin{abstract}
Chilean law diverse voices are used to generically identify traded in the stock market, such as: "securities", "commercial papers", "financial instruments", "values" among others, with similar meanings. As the transaction object represents various types of events, it seems reasonable to establish a common name, and ruled that the terms used are similar so far beyond the frequent use
\end{abstract}

Recibido el 8 de marzo y APROBADo el 1 de diciembre de 2016

* Este trabajo fue compuesto como parte del proyecto de investigación patrocinado por el Fondo de Investigación Científica y Tecnológica, con el título de "Los valores ante su depósito y eventual desmaterialización en el derecho chileno".

** Doctor en Derecho. Profesor emérito en la Facultad de Derecho de la Pontificia Universidad Católica de Valparaíso. Dirección postal Avda. Brasil 2950, Valparaíso, Chile. Correo electrónico: alejandro.guzman@pucv.cl

*** Doctor en Derecho, Magíster en Derecho y en Administración y Dirección de Empresas. Profesor adjunto en la Facultad de Derecho de la Pontificia Universidad Católica de Valparaíso. Dirección postal Avda. Brasil 2950, Valparaíso, Chile. Correo electrónico: jose.guerrero@pucv.cl 
denominación común, y descartar que las expresiones hasta ahora utilizadas sean análogas, más allá del uso frecuente que se les aplique por los operadores jurídicos. De esta manera, se propone, atendida la evolución del derecho en la materia, que la noción de "valor" cumple adecuadamente con la finalidad aglutinadora prevista para identificar genéricamente al objeto de transacción en el mercado de valores.

\section{Palabras ClaVe}

Valor, valores negociables, títulosvalores, efectos de comercio, mercado de valores, instrumentos financieros. them apply for legal operators. Thus, it is proposed, considering the evolution of law in the matter, that the notion of "value" adequately meets the unifier purpose expected to identify, generically, the traded object in the stock market.

\section{KEYWORDS}

Securities, negotiable values, financial instruments, securities market.

\section{ANTECEDENTES PREVIOS A LA Ley No 18.045 DE 1981 SOBRE "MerCADO DE VALORES"}

\section{Inexistencia de un reconocimiento legal de la noción de "valor" antes de 1981}

La diversidad de expresiones utilizada para denominar al objeto de transacción en un mercado de valores se explica porque si bien existieron en Chile transacciones de acciones, bonos y otros títulos desde principios del siglo XIX, no fue sino hasta el año 1981 que hubo de ser emitida una ley para regular el respectivo mercado, cuyo artículo 3 entrega una conceptualización de "valor", en cuanto objeto de transacción en el mercado. Nos referimos a la Ley N $\mathrm{N}^{\circ} 18.045$ sobre "Mercado de valores" (D. O. de 22 de octubre de 1981; en adelante: LMV.).

Antes de la ley citada no existió una definición legal de valor en Chile, a pesar de que la práctica de su transacción se remonta a la mitad del siglo XIX con la emisión de la Ley de sociedades anónimas promulgada el 8 de noviembre de 1854. Durante la primera mitad de ese siglo había habido intentos de organizar sociedades por acciones. De hecho, la más antigua fue la "Sociedad Canal del Maipo" organizada en 1827 para hacerse cargo de las reparaciones y de la administración del Canal San Carlos, cuya existencia fue reconocida por un decreto de 25 de abril de $1828^{1}$.

${ }^{1}$ Couyoumdjian, Juan Ricardo - Millar, René - Tocornal, Josefina, Historia de la Bolsa de Comercio de Santiago 1893-1993. Un siglo del mercado de valores en Chile, Santiago, Editorial Universitaria, 1993, p. 22. Los autores mencionan sobre el 
Hasta 1981, la regulación de las actividades del mercado se limitó a sus agentes; así, respecto de los intermediarios o corredores, existieron estatutos normativos desde fines del siglo XVIII, pues en 1796 fue librado un Reglamento de corredores que tuvo su base en las "Ordenanzas de Bilbao", de 1737, en cuanto establecían normas para las actividades de los corredores de comercio.

Hasta el año 1981 no hubo, pues, reglas para las operaciones mismas, que quedaron entregadas al derecho común, inicialmente representado por el derecho civil y después por el Código de Comercio, cuando éste fue promulgado en 1865. Antes de 1981, la legislación chilena tampoco reconoció la existencia de principios generales aplicables al mercado. No fue extraño, en consecuencia, que tampoco hubiera habido una denominación exclusiva para el mercado y para sus objetos de transacción.

Constituyeron alguna excepción en el país las operaciones de bolsas de valores. Éstas se remontan al siglo XIX; primero de modo informal con corretajes de valores y salas de corredores; en 1892 se creó el salón de corredores de Valparaíso; luego, en 1893, se constituyó formalmente la Bolsa de Comercio de Santiago y en 1898, como una sociedad de hecho, la Bolsa de Corredores de Valparaíso². Estas instituciones fueron objeto de autorregulación; sólo en 1924 la Junta Militar que entonces tomó el poder, luego de deponer al presidente Arturo Alessandri Palma, emitió un decreto-ley de 13 de noviembre de $1924^{3}$ que fue la primera norma legal que reglamentó las operaciones bursátiles. Por lo que atañe a las acciones de sociedades anónimas, éstas se sometían a las normas que le fueran aplicable de la Ley de sociedades anónimas de 1854 y a sus modificaciones posteriores.

\section{La expresión "efectos públicos" del artículo 68 del Código de Comercio chileno de 1865 \\ El Código de Comercio, promulgado en 1865, contenía en su texto original un artículo 68 que, a propósito de las actuaciones de los corredo- res -entre ellos los corredores de bolsa-, reconoce la noción de "efectos públicos", a la cual la doctrina chilena ha prestado poca importancia, pese a que ese artículo ha estado vigente desde que el Código fue promulgado. \\ El artículo $3 \mathrm{~N}^{\circ} 12$ CCom. declara como acto de comercio a las}

punto un trabajo inédito de Víctor Toledo titulado "Antecedentes de las sociedades anónimas y mercado de valores en Chile de la Independencia a 1855”, Instituto de Historia, Pontificia Universidad Católica de Chile, 1987, p. 8.

${ }^{2}$ Véase Couyoumdjian, Juan Ricardo, El alto comercio de Valparaíso y las grandes casas extranjeras, 1880-1930: una aproximación, en Historia, 33, Santiago, Pontificia Universidad Católica de Chile, 2000, pp. 63-99.

${ }^{3}$ Ibíd., pp. 109-114. 
operaciones de bolsa, y luego, a propósito de los corredores, en su antes citado artículo 68, establece: "Bajo la denominación de efectos públicos, se comprenden: $1^{\circ}$ Los títulos de créditos contra el Estado reconocidos como negociables, $2^{\circ}$ Los de establecimientos públicos y empresas particulares autorizadas para crearlos y hacerlos circular; $3^{\circ}$ Los emitidos por los gobiernos extranjeros, siempre que su negociación no se encuentre prohibida".

El hecho de que esta norma haga parte de la regulación de los corredores denota una característica especial: Se trata de "efectos" ${ }^{4}$ que son objeto de emisión, intermediación, negociación y circulación; por tanto, entendemos que son efectos -documentos o valores mercantiles- de oferta pública en el mercado, emitidos por entidades públicas o privadas como lo reconoce el propio $\mathrm{N}^{\circ} 2$ del artículo 68 CCom. ("establecimientos públicos y empresas particulares autorizadas para crearlos y hacerlos circular").

Por lo anterior, estimamos que no cabe restringir el adjetivo "público", componente de la expresión "efectos públicos", a las emisiones del Estado o de los órganos estatales, pues el propio artículo $68 \mathrm{~N}^{\circ} 2$ se refiere también a los emitidos por empresas particulares autorizadas para emitirlos.

Contra esta visión se manifiesta Ricardo Sandoval quien critica que, para los efectos del concepto establecido por el artículo 68 CCom., algunos piensen que las acciones de las sociedades anónimas sean "efectos públicos", ya que, según él, ello estaría en contradicción con el carácter taxativo de la enumeración del propio artículo $68^{5}$, que no las incluye.

No compartimos esta opinión pues las sociedades anónimas son empresas particulares autorizadas por la ley para emitir acciones y hacerlas circular, con lo cual se cumple con lo dispuesto en el $\mathrm{N}^{\circ} 2$ del artículo 68 CCom.

Por lo tanto, creemos que la expresión "efectos públicos" utilizada por el artículo 68 CCom. es una noción bastante más próxima a la de "valores" incluida en el artículo 3 de la Ley $\mathrm{N}^{\circ} 18.045$, que otras expresiones tales como "efectos de comercio" o "títulos de crédito" que son tradicionalmente utilizadas por la doctrina chilena para referirse indistintamente a los valores o a los títulos-valor y para identificar a las letras de cambio, cheques o pagarés ${ }^{6}$ que normalmente carecen de oferta pública en el mercado. La

${ }^{4}$ De acuerdo con el Diccionario de la Real Academia, 22a edición, Madrid, 2001, la $5^{\text {a }}$ acepción de "efecto" es: "Documento o valor mercantil, sea nominativo, endosable o al portador".

5 Sandoval López, Ricardo, Derecho comercial, 7a edición, Santiago, Editorial Jurídica de Chile, 2007, I/1, p. 125.

${ }^{6}$ Véase Lara Aguayo, Edinson, Teoría general de los títulos valores en el derecho chileno, Santiago, LegalPublishing - Thomson Reuter, 2013. En esta obra que como su nombre lo señala su objeto son los títulos valores, más de la mitad de ella, se concentra en analizar sólo las letras de cambio. 
oferta pública es una característica relevante, aunque no exclusiva, de los valores, en particular para su transacción en el mercado de valores formal; y ella explica los principios inspiradores de la Ley del mercado de valores: equidad o igualdad en la concurrencia al mercado, competencia, orden y transparencia del mercado ${ }^{7}$.

\section{La NOCión de “VALOR” en La Ley N 18.045 DE 1981 SOBRE "MERCADO DE VALORES", Y OTROS TEMAS}

\section{Motivación de la Ley $N^{\circ} 18.045$ sobre "Mercado de valores"}

La ausencia de una ley general del mercado de valores se prolongó hasta 1981, en que curiosamente nuevamente un Gobierno Militar -el anterior en 1924 reglamentó por primera vez con rango legal, como vimos, las operaciones de bolsa-, estimó necesario emitir una normativa reguladora del mercado de valores o capitales -se utilizan ambas denominaciones en los antecedentes legislativos-, basado, según el "Mensaje" presidencial a la Junta de Gobierno, en que el desarrollo del mercado financiero era un factor fundamental dentro de la estrategia de desarrollo económico y social implementada por el Gobierno Militar'.

El "Mensaje" del proyecto de ley señala que dentro del mercado financiero se distinguen dos grandes áreas: una es el de la banca e instituciones similares y otra es el del mercado de capitales propiamente tales o mer-

${ }^{7}$ El artículo 39 de la Ley $\mathrm{N}^{\circ} 18.045$ de Mercado de valores enuncia, a propósito de las Bolsas de Valores, las características de este mercado al establecer: "Las bolsas de valores deberán reglamentar su actividad bursátil y la de los corredores de bolsa vigilando su estricto cumplimiento de manera de asegurar la existencia de un mercado equitativo, competitivo, ordenado y transparente".

${ }^{8}$ Según Calderón Torres, Pablo, Mercado de capitales. Una mirada retrospectiva, en Revista de Estudios Tributarios, Santiago, Centros de Estudios Tributarios, Universidad de Chile, p. 4 (disponible solo en versión electrónica, en http://www. cetuchile.cl/images/docs/02._mercado_de_capitales_una_mirada_en_retrospectiva_pablo_calderon.pdf [fecha de visita: 2 de diciembre de 2015]), a principios de la década del 70 con el control del Estado en grandes áreas de la economía en el gobierno del presidente Salvador Allende, en términos financieros existía un control estricto sobre las tasas de interés, sobre la asignación del crédito y gran parte del sistema bancario estaba en manos del Estado. "A raíz de esto a fines de 1973 en Chile no existía un mercado de capitales propiamente tal, pero, luego de superado el 'shock' político de ese año, las transformaciones económicas que comenzaron a operar en Chile fueron paulatinamente dejando atrás la fuerte contracción económica vivida y aquel complejo panorama descrito. Es así que el país comenzó rápidamente a ser dispuesto para una apertura económica que partió por liberar al mercado financiero, lo que justificaría la necesidad de regular tanto el mercado bancario como el mercado de capitales o valores. 
cado de valores, en que se transan las acciones de sociedades anónimas y los instrumentos de deuda a mediano y largo plazo, que permiten a las empresas captar a plazo fondos del público, convenientes para llevar a cabo proyectos de inversión necesarios para el desarrollo del país. En esta segunda área del mercado financiero se pretendía con la Ley del mercado de valores dar una fisonomía definitiva a la estructura financiera de Chile?

\section{La noción de "valor" del artículo 3 de la Ley $N^{\circ} 18.045$}

La Ley No 18.045 sobre Mercado de valores, de 22 de octubre de 1981, llenó o intentó llenar el vacío respecto del reconocimiento legislativo a un concepto genérico del objeto de transacción del mercado, denominado indistintamente "de capitales" o "de valores".

El artículo 3 inciso $1^{\circ}$ de la Ley $\mathrm{N}^{\circ} 18.045$ dispone: "Para los efectos de esta ley, se entenderá por valores cualesquiera títulos transferibles incluyendo acciones, opciones a la compra y venta de acciones, bonos, debentures, cuotas de fondos mutuos, planes de ahorro, efectos de comercio y, en general, todo título de crédito o inversión".

La ley, pues, caracteriza los valores como títulos transferibles; y luego individualiza a las acciones, opciones a la compra y venta de acciones, bonos, cuotas de fondos mutuos, planes de ahorro y efectos de comercio, como tipos o especies de valores.

La lista que ofrece la ley sobre tipos o especies de valores no es un "numerus clausus" sino cierta enumeración meramente ejemplar, ya que, a efectos de no restringir el concepto, entrega características generales que deben tenerse en cuenta para mirar a otros títulos como un valor, porque, en efecto, se trata de cualquier título transferible y, en general, de todo título de crédito o inversión.

Cabe destacar que la conceptualización legal no bien ataña a "valores", además incluye, como característica o elemento de éstos, a la noción de "título", esto es, el documento en que consta el valor, lo que en Chile a la fecha de la promulgación de la ley no era extraño, y por ello que se utilizaba -y aún se sigue utilizando- la noción de "título-valor".

Sin embargo, la Ley $\mathrm{N}^{\circ} 18.876$ sobre Constitución y operación de entidades privadas de depósito y custodia de valores (D.O. de 21 de diciembre de 1989) recogió por primera vez en Chile la práctica de la "desmaterialización" al permitir la anotación de valores en cuenta. Según ello, ya no es más verdadero que todos los valores sean títulos-valor. Lo que cabe decir,

9 "Mensaje" del presidente de la República a la Junta de Gobierno de 30 de diciembre de 1980, en Historia de la ley 18.045, Biblioteca del Congreso Nacional, pp. 4-7, disponible en formato electrónico en http://www.bcn.cl/historiadelaley [fecha de visita el 27 de marzo de 2016]. 
pues, es que los valores pueden ser, ora materializados y manifestarse en un título, ora desmaterializados y constar en anotaciones en cuenta. Por ello, si queremos referirnos al género, es apropiado hablar simplemente de "valores", como lo hace el artículo 3 de la Ley $\mathrm{N}^{\circ} 18.045$, aun cuando la definición que les atribuye los vincule a los títulos, de modo de tener que ser corregida la descripción legal, para adaptarla al nuevo fenómeno de la desmaterialización. Sin embargo, nada hay que objetar a la denominación genérica de "valores", que cabe, pues, mantener.

\section{Evolución de la noción de "valor" del artículo 3 de la Ley $N^{\circ} 18.045$}

Como se ha anticipado, la noción de "valor" del artículo 3 de la Ley $\mathrm{N}^{\circ}$ 18.045 ha sido el primer reconocimiento legal de dicha noción, aunque haya tenido lugar recién en 1981. Eso le da un especial y relevante carácter en el derecho chileno, aun cuando se restrinja el uso del concepto definido sólo al ámbito de la ley del mercado de valores, ya que el artículo 3 se inicia con estas palabras: "Para los efectos de esta ley se entenderá por valores [...]".

La noción de "valor" del artículo 3 recoge de manera adecuada lo que al año 1981 podía entenderse como valor en Chile. Sin embargo, la evolución posterior ha sido dinámica, probablemente impulsada precisamente por esta primera ley del mercado de valores, que, junto a la transformación del modelo económico del país ha impulsado el mercado financiero chileno y, en particular, el mercado de valores. Cabe recordar que la ley que modificó el sistema de pensiones chileno, permitiendo invertir en el mercado financiero los fondos de pensiones de los trabajadores chilenos también data de 1981.

Parte de esa evolución posterior a 1981 ha llevado a que el concepto de "valor" deba ser sometido a una doble revisión: por un lado, en cuanto a su vinculación con la noción de "título" como consecuencia del fenómeno de la "desmaterialización" de los valores, a que se aludió antes; y, por otro, en cuanto a la denominación de algunos de los tipos de valores que se mencionan, en cuanto han caído en desuso, como es el caso de los "debentures"; o que han adquirido un nuevo significado que es importante reconocer para evitar confusiones, como acaece con la expresión "efectos de comercio"; o que sea necesario introducirles una delimitación, como ocurre en la figura de los "títulos de crédito", pues los hay que no consisten en "títulos". Igualmente parece conveniente, para los efectos de la Ley del mercado de valores, que se indique en el concepto de "valor" ser una característica esencial tratarse de objeto susceptibles de oferta pública, ya que sólo a ellos se aplica la Ley de mercado de valores. De hecho, solo a los valores de oferta pública se restringirá esta investigación, la cual no se extenderá, por ende, a los valores que no sean objeto de tal oferta y que 
se entienden como transacciones privadas, como lo expresa el artículo 1 inciso $2^{\circ}$ de la Ley $\mathrm{N}^{\circ} 18.045$.

4. Critica a la identificación usual de las expresiones "efectos de comercio" $y$ "títulos de crédito" para designar genéricamente a los "valores"

Desde la publicación de la Ley $\mathrm{N}^{\circ} 18.045$ el 22 de octubre de 1981, el uso de las expresiones "efectos de comercio" y "títulos de crédito" para mentar al objeto genérico de transacción del mercado ha ido en lenta retirada.

La expresión "efectos de comercio" ha sido reducida a un tipo específico de objeto transable; propiamente, a las obligaciones de oferta pública de corto plazo.

A su turno, la expresión "título de crédito" se identifica con la letra de cambio, el cheque y el pagaré, que no necesariamente son objetos de transacción en el mercado de valores. Esa expresión, por cierto, no comprenden todos los objetos que se transan en él, como son, por ejemplo, las acciones, las cuotas de fondo de inversión o los derivados financieros, por lo que procede descartar su uso en un sentido genérico de identificación del objeto de transacción del mercado de valores.

Desde la publicación en 1981 de la Ley del mercado de valores se ha utilizado por la doctrina chilena con mayor frecuencia la expresión "títulos-valor". Sin embargo, ésta se suele identificar, como una noción sinónima, con la de "títulos de crédito"10; o bien, cuando se trata de los títulos-valor, se termina por reducir los títulos de crédito a unas figuras que claramente no son títulos-valor o valores propiamente tal, como es el caso de las letras de cambio ${ }^{11}$.

Desde la emisión de la Ley $\mathrm{N}^{\circ} 18.045$, creemos que, al menos para las transacciones en los mercados formales o regulados, son perfectamente distinguibles los "títulos-valores" de los "títulos de crédito", en cuanto los primeros requieren necesariamente de su oferta pública. Luego, con el

10 A vía de ejemplo, Contreras Strauch, Osvaldo, Instituciones de derecho comercial, Santiago, LexisNexis, 2005, II, p. 921, hace sinónimos los conceptos de "título de crédito" y "títulos-valor", pues señala: "La denominación tradicional es la de 'títulos de crédito'; pero, poco a poco, ha ido extendiéndose el uso de la expresión 'títulos valores' [..] En la presente obra utilizaremos indistintamente ambas denominaciones”. En igual sentido, BAEZA Ovalle, Gonzalo, Tratado de derecho comercial, Santiago, LexisNexis, 2008, III, p. 1.157, dice "Resulta razonable usar indistintamente los apelativos de "título de crédito" o "título valor" al ser los más cercanos al concepto que con ellos es deseado involucrar y, por lo demás, tales denominaciones constituyen las que más frecuentemente han sido empleadas por los distintos autores".

${ }^{11}$ Como es el caso de Lara Aguayo, Edinson, en su Teoría general de los títulos valores (n. 6). 
reconocimiento en Chile del fenómeno de la “desmaterialización” de los títulos valores, creemos que son perfectamente distinguibles las expresiones "títulos-valor" y "valor", precisamente sobre la base de si constan o no en un título o documento. Por ello, la expresión genérica debe ser "valor", que ha de comprender tanto a los "títulos-valor" cuanto a los "valores desmaterializados".

El legislador, pese a que la fecha de la publicación de la Ley de mercado de valores en 1981, aun no se reconocía el fenómeno de la "desmaterialización” de "títulos-valor" en Chile, hizo bien en utilizar en su artículo 3 la denominación de "valor" y no de "títulos-valor", sin perjuicio ser ahora necesario actualizar el contenido de la definición.

5. Sobre la limitación o insuficiencia del uso de la expresión "efectos de comercio" para identificar a un objeto especifico: valores de deuda de oferta pública de corto plazo

Tradicionalmente se ha entendido en la doctrina chilena por "efecto de comercio" a una especie de título de crédito representativo de cierta obligación de dinero, por pagar en el corto plazo, entendiendo por este último al término que no exceda de un año; el ejemplo clásico de un efecto de comercio es la letra de cambio, que, a su vez, es título de crédito ${ }^{12}$.

La utilización de la noción de "efecto de comercio" en Chile se ha basado en la doctrina francesa de los "effets de commerce". Esta expresión ha sido atribuida a todos aquellos títulos que sirven al comerciante de manera semejante al dinero y a los cuales es reconocido un poder liberatorio determinado ${ }^{13}$. A partir de esta noción vinculada a los medios de pago distintos al dinero, utilizados normalmente en el comercio, como letras de cambio y cheques, se fue extendiendo, creemos que erróneamente, su uso para comprender genéricamente a todos los "títulos-valor".

De esta manera, se observa en la doctrina chilena que la denominación de "efectos de comercio" ha sido atribuida a todos aquellos títulos que sirven al comerciante de manera semejante al dinero y a los cuales es reconocido un poder liberatorio determinado. Así que en tal denominación se encuentran reunidas las características fundamentales que denotan a todos los "títulos-valor" o circulatorios, como son las de configurar un documento negociable ${ }^{14}$.

Lo anterior constituye un error. Si se sigue a Georges Ripert ${ }^{15}$, uno

12 Véase Ubilla Grandi, Luis, Teoría general de la letra de cambio y pagaré en la Ley 18.092, Santiago, Editorial Jurídica de Chile, 1990, p. 13

${ }_{13}$ Baeza Ovalle, Gonzalo, Tratado de derecho comercial (n. 10), III, p. 1.575.

${ }^{14}$ Ibíd.

${ }^{15}$ Entre los autores chilenos que siguen la conceptualización de George Ripert 
de los autores franceses de mayor influencia en la doctrina chilena, él reservaba la expresión "efectos de comercio" para los efectos negociables que facilitan el comercio y la circulación, en especial, para las letras de cambio y los cheques ${ }^{16}$. Cabe mencionar que originalmente estos títulos negociables se utilizaban únicamente en el comercio y de ahí su nombre de "efectos de comercio" ${ }^{17}$ que Ripert define como "un titre négociable qui constate l'existence au profit du porteur d'une créance à court terme et sert à son paiement" ("un título negociable que reconoce la existencia, en favor del portador, de una deuda a corto plazo y se utiliza para su pago") ${ }^{18}$. Ripert vincula el concepto particularmente con las operaciones bancarias ${ }^{19}$ y lo entiende bajo la perspectiva de servir como un medio de pago alternativo al dinero y referido a obligaciones de corto plazo.

El célebre autor francés utiliza, además, la noción de "valores mobiliarios" que se caracterizan por la naturaleza del derecho que representan, pues se trata de un derecho de socio o de prestamista a largo plazo ${ }^{20}$, siempre susceptible de un rédito a su titular ${ }^{21}$, lo que no sucede con medios de pago alternativos al dinero como cheques o letras, por lo cual Ripert descarta expresamente que puedan entenderse como valores mobiliarios los efectos de comercio que no generen intereses o réditos ${ }^{22}$.

sobre efectos de comercio, véase Morales Barría, Fernando, Prenda de valores mobiliarios a favor de los bancos, Memoria de prueba, Universidad Católica de Chile, Santiago, 1964, p. 9; UBILLA GRANDi, Luis, Teoría general de la letra de cambio y pagaré en la Ley 18.092, Santiago, Editorial Jurídica de Chile, 1990, p. 13; y VÁSQUEZ MÉndez, Guillermo, Tratado sobre el cheque. Historia, legislación, doctrina y jurisprudencia, Santiago, Editorial Jurídica de Chile, 2000, p. 204.

${ }^{16}$ Por el uso tradicional de la expresión "efecto de comercio", véase TouzAud, Daniel, Des effets de commerce. Étude de législation comparée, Paris, L. Larose - Forcel, 1882 , pp. 29 ss.

17 Ibíd.

18 Véase RiperT, Georges, Traité élémentaire de droit commercial, 6a édition, Paris, Librairie Générale de Droit et de Jurisprudence, 1970, II, p. 4.

${ }^{19}$ Véase RiperT, Georges, Traité élémentaire de droit commercial, 6a édition, Paris, Librairie Générale de Droit et de Jurisprudence, 1968, p. 1.026.

${ }^{20}$ Ibíd., p. 852

${ }^{21}$ Ibíd., p. 854

22 Señala al respecto Georges Ripert, ibíd.: "Les valeurs mobilières sont caractérisées par la nature du droit qu'elles représentent. Ce droit est un droit d'associé ou de préteur, c'est-à-dire un droit susceptible de procurer un revenu à son titulaire. $\mathrm{Ne}$ constituent donc pas des valeurs mobilières ni les billets de banque qui ont un rôle monétaire, ni les effets de commerce et le chèque qui ne portent pas intérêt, ni les coupons donnant droit au paiement d'un dividende ou d'un intérêt ou à un droit de souscription". ("Los valores mobiliarios se caracterizan por la naturaleza del derecho que ellos representan. Este derecho es un derecho de asociado o de prestamista, es de- 
Por ello, creemos que, de seguirse la doctrina francesa tradicional, debió utilizarse la expresión genérica de "valores negociables" que ya utilizó Ripert cuando analiza las operaciones en Bolsas de Valores ${ }^{23}$, en vez de la expresión "efectos de comercio" que el propio Ripert restringía a los de corto plazo.

Por lo anterior, la identificación que tradicionalmente se hace de los "efectos de comercio" y de los "títulos-valor" o "valores" o "valores negociables", en cuanto atribuida a Georges Ripert, es incorrecta ya que, como hemos señalado, este autor distingue los "efectos de comercio" de los "valores negociables" por lo que tal identificación que tiende a ser generalizada en el derecho chileno, sería una interpretación original de los autores que la utilizan ${ }^{24} \mathrm{o}$ bien derechamente un error si fundan su argumentación en Ripert.

Cabe añadir que la identificación común de los efectos de comercio es con instrumentos de deuda normalmente de corto plazo, como las letras de cambio, los cheques o los pagarés, por lo que la pretensión de utilizar la expresión "efecto de comercio" para identificar genéricamente al objeto de transacción del mercado de valores es insuficiente ya que no comprendería a valores que representan deudas de largo plazo, como los bonos, ni a valores como las acciones, entendiendo éstas también como un crédito de largo plazo de los accionistas contra la propia sociedad al momento de su liquidación.

La práctica de los operadores del mercado, probablemente sin mayor razonamiento jurídico, parece haber advertido la insuficiencia de la expresión "efectos de comercio" para comprender a todo tipo de valores, y ha dado una nueva significación a la expresión, que, por lo demás, ha sido recogida por la Superintendencia de Valores y Seguros. Según tal significación, se identifica como "efectos de comercio" a los "títulos-valor" de oferta pública, representativos de deuda de corto plazo, es decir, a los denominados "pagarés de empresa" que se emiten en el mercado para que las empresas obtengan financiación. Ha sido la propia Superintendencia de Valores y Seguro, en efecto, la que ha definido a los efectos de comercio como: "Títulos de deuda de corto plazo que se colocan y se transan en el mercado de valores. El plazo máximo es de 36 meses"25.

Lo anterior es llamativo, porque la Ley $\mathrm{N}^{\circ} 18.045$, en su artículo 131,

cir, un derecho susceptible de procurar un ingreso a su titular. No constituyen, pues, valores mobiliarios ni los billetes de banco que tienen una función monetaria, ni los efectos de comercio y el cheque que no contienen interés, ni los cupones que dan derecho a un pago de un dividendo o de un interés o a un derecho de suscripción”).

${ }^{23}$ Ibíd., p. 852.

24 Véase la n. 15.

25 Véase Superintendencia de Valores y Seguros, "Efectos de Comercio" dispo- 
para referirse a emisiones de deuda de hasta 36 meses, utiliza la expresión "pagarés u otros títulos de crédito", pero no menciona a los "efecto de comercio". Esa norma dispone en efecto: "Sin perjuicio de lo establecido por el artículo 103 de esta ley, la oferta pública de valores representativos de deuda cuyo plazo no sea superior a 36 meses, también podrá efectuarse mediante la emisión de pagarés u otros títulos de crédito [...]". El artículo 103 expresa, a su turno: "La oferta pública de valores representativos de deuda cuyo plazo sea superior a un año, sólo podrá efectuarse mediante bonos [...]”. Por lo anterior, la referencia del artículo 131 al artículo 103, ambos de la Ley $\mathrm{N}^{\circ}$ 18.045, implica entender que una emisión de deuda de oferta pública de plazo entre 12 y 36 meses puede ejecutarse mediante emisión de bonos, o bien de pagarés u otros títulos de crédito; y que, una emisión de valores representativos de deuda, de plazo de pago inferior a 12 meses, sólo puede ser operada mediante pagarés u otros títulos de crédito.

Como se aprecia, la Ley $N^{\circ} 18.045$ no utiliza la expresión "efecto de comercio" para la oferta pública de valores representativos de deuda de corto plazo -inferior a 36 meses-; más aún, un valor de plazo inferior a 36 meses pero superior a 12 meses podría ser emitido como bono. No obstante ello, la Superintendencia de Valores y Seguros, denomina "efectos de comercio" a todo título de deuda de plazo inferior a 36 meses, y así los identifica en el Registro de Valores.

Por lo señalado, tanto en su significación tradicional como en aquella que hoy le otorgan los agentes del mercado de valores y la propia Superintendencia de Valores y Seguros, los efectos de comercio se refieren a obligaciones de corto plazo, lo que nos permite descartar su uso como una denominación aplicada al objeto genérico de contratación del mercado de valores, el que comprende, entre otras, operaciones y actos de corto y largo plazo; por lo que cabe, pues, desechar, descartar su utilización para el objetivo de definir al género.

Reafirma lo anterior el hecho de que la expresión genérica "efecto de comercio" se vincule tradicionalmente con la letra de cambio, el cheque, el pagaré y otros instrumentos similares, los cuales suelen estar conectados con una operación comercial específica y, en su origen, son causados por transacciones privadas, con lo cual no cumplen con un requisito básico --la oferta pública- para que puedan ser objeto de transacción en el mercado de valores regido por la Ley $\mathrm{N}^{\circ} 18.045$.

nible en: http://www.svs.cl/educa/600/w3-propertyvalue-558.html [fecha de visita: 1 de septiembre de 2016]. 


\section{Sobre el desuso de la expresión "debenture"}

La expresión "debenture", a la que hace referencia el artículo 3 de la Ley $\mathrm{N}^{\circ} 18.045$, se ha utilizado como sinónimo de "bono", y en algunos casos se intentó caracterizar con ella al bono convertible en acciones.

Sin embargo, "debenture" es una expresión que, por su desuso y su sinonimia con la expresión "bono", debe dejar de utilizarse, ya que conduce a errores en los agentes del mercado, quienes entienden que pueden tener características distintas a los bonos.

La propia Superintendencia de Valores y Seguros habla de los bonos "antes conocidos como 'debentures"'26.

\section{LA NOCIÓN DE “INSTRUMENTO FINANCIERO” DEL ARTí́CULO 1 DE LA LEY Nº 20.345}

La Ley No 20.345 sobre Sistemas de compensación y liquidación de instrumentos financieros (D. O. de 6 de junio de 2009), en su artículo $1 \mathrm{~N}^{\circ} 8$ define que debe entenderse por "instrumentos financieros" a los "valores de conformidad a lo establecido en el artículo $3^{\circ}$ de la ley $N^{\circ} 18.045$, sobre Mercado de Valores y, en general, cualquier titulo, derecho, acto, contrato, factura, producto o moneda extranjera, negociables en mercados nacionales o extranjeros. En todo caso, se excluye la moneda nacional'.

Esta disposición, nos permite pensar que todo valor, en los términos del artículo 3 de la Ley de mercado de valores (y no Ley "sobre" mercado de valores como dice el artículo $1 \mathrm{~N}^{\circ} 8$ de la ley en comento), es un instrumento financiero, pero no todo instrumento financiero es un valor ${ }^{27}$, como sería el caso de unas facturas o ciertas divisas, ambos objetos de transacción en el mercado financiero general pero no en el mercado de valores específico.

Esta definición legal al establecer un objeto genérico de transacción, como los instrumentos financieros, nos permite concebir un mercado financiero genérico, el cual cuenta con una serie de mercados o submercados, uno de los cuales es el mercado de valores. Por ello, desde la emisión de la Ley $\mathrm{N}^{\circ} 20.347$ en el año 2009, existe una clara diferenciación de género a especie entre las nociones de "instrumento financiero" y de "valores", por lo que, si bien un valor es un instrumento financiero, es más preciso utilizar la noción de "valor" como objeto de contratación en el mercado de valores. El empleo de la expresión "instrumento financiero" para ne-

${ }^{26}$ Véase http://www.svs.cl/sitio/discapacidad/inversionista/pop_8.php [fecha de visita el 17 de agosto de 2016].

27 Véase Guzmán Brito, Alejandro, El contrato de préstamo de valores, en Revista de Derecho de la Pontificia Universidad Católica de Valparaíso, 38, $1^{\mathrm{er}}$ semestre, Editorial Universitaria, Valparaíso, 2012, pp. 170-171 
gociaciones en el mercado de valores puede inducir a error, ya que varios de los que obedecen a esa denominación no podrían ser transados en el mercado de valores, particularmente porque carecen de una característica esencial, más allá de la transferibilidad, que es el hecho que deben originarse en ofertas públicas al mercado.

\section{SOBRE El uso de “VALOR” COMO ObJeTO GENÉRICO}

DE TRANSACCIÓN EN EL MERCADO EN FUNCIÓN DE EXCLUIR

LAS NOCIONES DE “CAPITAL”, “TÍTULOS-VALOR”, “VALOR NEGOCIABLE” O “INSTRUMENTO FINANCIERO”

El objeto genérico de transacción en los mercados de valores, como su propia denominación anuncia, son "valores", ya sea que se les denomine "títulos-valor", "valor negociable" o simplemente "valor". Nosotros preferimos usar esta última denominación genérica, porque es comprensiva tanto de los "títulos-valor" como de aquellos valores surgidos de la desmaterialización de los títulos ${ }^{28}$, que aún así mantienen la esencia de un valor, en cuanto representan un derecho o un valor, para una o ambas partes.

a) Por lo que atañe a la exclusión del término "capital" para denominar al objeto genérico de transacción en el mercado de valores, pensamos que ese término es equívoco, ya que existen varios valores que no representan capital en sentido estricto.

Su uso es coherente con la utilización generalizada del término "mercado de capitales" para referirse al conjunto de los mercados financieros; se relaciona con la idea del flujo circular de la economía, en que los flujos monetarios de las familias, se trasladan, vía ahorro, a financiar a las empresas, por lo que se aporta capital a éstas a través de estas transacciones financieras.

Estimamos que tal visión puede considerarse errónea desde la perspectiva económica -que en este ámbito no puede desligarse de la jurídicaporque el objeto de transacción en estos mercados, en términos genéricos,

${ }^{28}$ Sobre el fenómenos de la "desmaterialización" de los títulos valores, véase: Caballero Germain, Guillermo, La adquisición a non domino de valores anotados en cuenta, Madrid, Civitas, 2010; CoRTÉs GARCÍA, Eduardo La desmaterialización de los títulos valores, Valladolid, Lex Nova, 2002; De Eizaguirre, José María, Derecho de los títulos-valores, Madrid, Civitas, 2003; EsPINA, Daniel, Las anotaciones en cuenta: un nuevo medio de representación de los derechos, Madrid, Civitas, 1995; GUZMÁn BRITO, Alejandro, La prenda sin desplazamiento de valores desmaterializados o emitidos sin impresión fisica del título que los evidencie, en Revista Chilena de Derecho, 38/1, Pontificia Universidad Católica de Chile, Santiago, 2011, pp. 57-88. Últimamente: CABALLERO Germain, Guillermo, La custodia en el mercado de valores. De los títulos de crédito a los valores anotados en cuenta, Santiago, Thomson Reuters, 2016. 
son instrumentos financieros, que representan activos financieros para una parte y pasivos financieros para la otra; siendo activos y pasivos financieros, no necesariamente representan capital.

La transacción de valores no es, en puro sentido económico, una transacción de capital, ya que capital en sentido económico es el factor productivo que permite generar bienes de capital, esto es, bienes que permiten producir otros bienes o servicios, o equipos y estructuras utilizadas para producir bienes y servicios ${ }^{29}$.

Siguiendo a los economistas Cristián Larroulet y Francisco Mochón, el capital en sentido económico, salvo que se especifique expresamente lo contrario, denota al capital físico, esto es, máquinas y edificios, y no al capital financiero. Así, un paquete de acciones no constituye un recurso productor de bienes y servicios, y no es capital en sentido económico ${ }^{30}$.

No cabe confundir el capital con las rentas de capital, concepto que se vincula al capital-dinero ${ }^{31}$. Las rentas del capital provienen del pago de factores productivos como el trabajo o el propio capital, y son las que se canalizan en consumo o ahorro. El capital-dinero es proveído por quienes canalizan sus flujos de ahorro a estos mercados, esto es, dinero como un capital autónomo que genera intereses, y que forma parte del circuito

${ }^{29}$ Mankiw, George, Principios de economía, México, Cengage, 2009, p. 406

30 Ver Larroulet Vignau, Cristian - Mochón Morcillo, Francisco, Economía, 2a edición, Santiago, McGraw-Hill Interamericana, 2003, p. 38. En igual sentido Samuelson, Paul - Nordhaus, William, Economía, traducción de Esther Tabasco y Luis Toharía, McGraw Hill, 2002, p. 235, señalan que el capital (o los bienes de capital) esta formado por los bienes duraderos producidos que se utilizan, a su vez, como factores productivos para producir más. Existen tres tipos de bienes de capital: las estructuras (como las fábricas y las viviendas), el equipo (los bienes de consumo duradero como los automóviles, el equipo duradero de producción, como las máquinas-herramientas y computadoras), y las existencias de factores y de productos.

${ }^{31}$ Las rentas de capital que financian inversiones se relacionan con el concepto de capital -dinero que Karl Marx consideró como una forma de capital, criticable, entre otras razones, por producir la aceleración por medio del crédito de las distintas fases de circulación o la metamorfosis del capital [...] transformando al capitalista realmente activo en un simple gerente, administrador de capital ajeno, y a los propietarios de capital [accionistas] en simples capitalistas de dinero. Véase MARX, Karl, El capital. Crítica a la economía politica, edición de México, Fondo de Cultura Económica, 1966, III, p. 414-415. A propósito del capital bancario, Marx (p. 437) señala "El curioso papel que aquí desempeña el capital hace que con el mismo cuidado con que la economía ilustrada procuraba inculcar la idea de que el dinero no es capital, procura esta economía de banqueros imbuir la noción de que en realidad el dinero es el capital por excelencia". 
capital-dinero, capital-mercancía y capital-productivo, como base del modo de producción capitalista ${ }^{32}$.

En el caso del ahorro, al concurrir al mercado financiero, él permite financiar la inversión o la necesidad de financiación.

Entonces, frente a las diversas alternativas de inversión de esas rentas de capital, una vez descontado el consumo, en la medida que exista un sistema financiero desarrollado, los agentes económicos, por lo general, no canalizan sus ahorros en forma directa hacia bienes de capital, sino que lo hacen de forma indirecta a través de la transacción de instrumentos financieros, esperando una retribución económica de los activos que representa el instrumento financiero respectivo. Por tanto, desde la perspectiva de la provisión de flujos monetarios, más que mercados de capitales, son mercados de rentas de capital, debiendo descartarse el uso del término "capital" como sinónimo de "valor".

b) Sobre la exclusión del término "títulos-valor": Se justifica por el fenómeno de la desmaterialización, del que hemos hablado, que ya no permite comprender a todo valor en la categoría de título ${ }^{33}$.

c) Sobre la exclusión del término "valor negociable": Tal denominación, si bien es correcta en cuanto los valores deben ser esencialmente transferibles, por lo mismo no deja de ser redundante, ya que si un valor no fuera negociable o transferible dejaría de ser un valor para los efectos de los mercados de oferta pública, por lo que sugerimos su no utilización ${ }^{34}$.

32 Ver Tavares, María - Mello Belluzo, Luiz, Capital financiero y empresa multinacional, en Estévez, Jaime - LichtenszTejn, Samuel (compiladores), Nueva fase del capital financiero. Elementos teóricos y experiencias en América Latina, México, Nueva Imagen, 1981, pp. 35-37

33 Ver la n. 28.

${ }^{34}$ Frente a la sugerida exclusión del término "valores negociables", debemos reconocer que en el derecho español la legislación reguladora del mercado de valores se ha superado la confusión terminológica acerca del objeto de transacción del mercado, optando por utilizar precisamente el término "valores negociables". Esta uniformidad terminológica comenzó en la Ley del mercado de valores $\mathrm{N}^{\circ}$ 24/1988, que tomó posición en su "Exposición de motivos" al señalar que: "La Ley reposa sobre el concepto de 'valores' o, para mayor precisión, de 'valores negociables', concepto dificil de definir de forma escueta en el articulado de un texto legal, pero no por ello carente de realidad. Así, se abandona, ante todo, la relación biunivoca dominante hasta hoy entre el mercado de valores y los 'títulos-valores'". El texto vigente fijado por el Real Decreto Legislativo $\mathrm{N}^{\circ} 4 / 2015$, de 24 de octubre de 2015, mantiene el uso del término "valores negociables", aun cuando mantiene el uso del vocablo "valores" para referirse al mercado: artículo $1 \mathrm{RDL}$ 4/2015: "La presente ley tiene por objeto la regulación de los mercados primarios y secundarios de valores [...]"; y el artículo 2: "Quedan comprendidos en el ámbito de la presente Ley los valores negociables emitidos por personas o entidades públicas o privadas, y agrupados en emisiones. Reglamentariamente se establecerán 
Igualmente, estimamos que el concepto de "valor" comprende a todos los valores que cumplan con las características de ser transferibles y estén destinados a la oferta pública. Lo mencionamos, ya que algunas normas de la Ley $\mathrm{N}^{\circ} 18.045$ parecieran diferenciarlos, como, por ejemplo, su artículo $5^{35}$ que, a propósito de la inscripción en el Registro de Valores, en su letra b) se refiere a los valores de oferta pública y en sus letras c) y d), a las acciones de sociedades anónimas abiertas, que voluntariamente $o$ por obligación legal desean registrar sus acciones, pareciendo diferenciar los conceptos de "valor" y "acción", en circunstancias que el primero genéricamente comprende al segundo, como se desprende del artículo 3 de la Ley No 18.045.

Creemos que el artículo 5 de la Ley No 18.045 sólo quiere dar cuenta de la especialidad de requisitos exigidos a las sociedades anónimas en cuanto tienen la obligación de inscribir sus acciones en el Registro de Valores de la Superintendencia de Valores y Seguros, bajío la cual expresión se comprenden a las sociedades anónimas abiertas y a aquellas sociedades anónimas cerradas que voluntariamente o por obligación legal en determinados casos deben registrar sus acciones en el mencionado Registro.

d) Por último, en cuanto a prescindir de la expresión "instrumento financiero" como término genérico para designar al objeto de transacción del mercado de valores: si bien aceptamos que esa ella puede comprender a los "valores", sucede que la propia definición de "instrumento financiero" del artículo $1 \mathrm{~N}^{\circ} 9$ de la Ley $\mathrm{N}^{\circ} 20.345$ señala a los instrumentos financieros como objetos de transacción en otros mercados distintos al de valores, como las facturas o la moneda extranjera, lo cual coincide con la idea de instrumento financiero como objeto genérico de contratación en el mercado financiero, que excede al de valores y comprende, además, al mercado del crédito y al mercado cambiario o de divisas.

los criterios de homogeneidad en virtud de los cuales un conjunto de valores negociables se entenderá integrado en una emisión".

${ }^{35}$ Artículo 5 de la Ley $\mathrm{N}^{\circ}$ 18.045: "La Superintendencia llevará un Registro de Valores el cual estará a disposición del público. En el Registro de Valores se deberán inscribir: a) Los emisores de valores de oferta pública; b) Los valores que sean objeto de oferta pública; c) Las acciones de las sociedades anónimas que tengan 500 o más accionistas o, a lo menos, el 10\% de su capital suscrito pertenezca a un minimo de 100 accionistas, excluidos los que individualmente o a través de otra personas naturales o jurídicas, excedan dicho porcentaje, $y \mathrm{~d}$ ) Las acciones emitidas por sociedades anónimas que voluntariamente asi lo soliciten o que por obligación legal deban registrarlas. La solicitud de inscripción de un emisor en el registro de valores deberá estar necesariamente acompañada de una solicitud de inscripción de los valores que dicho emisor ofrecerá públicamente. Sin embargo, no estarán obligados a ofrecer los valores inscritos sino hasta después que transcurra un año desde su registro". 
Si dichas facturas o monedas directa o indirectamente constan en un valor, ya no son facturas o monedas extranjeras sino un objeto distinto que ha de transarse en el mercado de valores. Por ejemplo, si las facturas son "securitizadas", el objeto de transacción será el bono "securitizado", o sean, un valor, y no las facturas en sí mismas. O bien, si unas operaciones en moneda extranjera constan en un contrato de futuros, el contrato mismo se transforma en un valor transable en el mercado de valores, que entre su sub-mercados puede contar a un mercado organizado de derivados financieros.

Debemos reconocer que el uso genérico de la expresión "valor" suscita críticas porque existen otros valores, como los bienes raíces, que valen en sí mismos. Para aplacar esas críticas, se podría utilizar la expresión "valor financiero"; pero, atendido que la expresión "valor" se utiliza en el contexto del mercado de valores, que forma parte del mercado financiero, no existe la posibilidad de una confusión como la señalada, por lo que creemos innecesaria esa precisión.

El uso de la expresión "valor" o "valores”, es por lo demás, la opción que ha seguido la legislación chilena, aún antes que se regulara la "desmaterialización", al definir la noción de "valor" - por más que después se refiera a "títulos-valor"- en el artículo 3 de la Ley $N^{\circ}$ 18.045, el cual, para evitar confusiones terminológicas, podría modificarse de la siguiente forma: "Para los efectos de esta ley, se entenderá por valores cualesquiera títulos o anotaciones en cuenta, representativos de derechos, deudas, crédito o participación en fondos mutuos o de inversión, emitidos en mercados primarios de oferta pública y esencialmente transferibles en los mercados secundarios".

\section{BiBLIOGRAFÍA}

BaEza Ovalle, Gonzalo, Tratado de derecho comercial, Santiago, LexisNexis, 2008, III. Caballero Germain, Guillermo, La adquisición "a non domino" de valores anotados en cuenta, Madrid, Civitas, 2010

Caballero Germain, Guillermo, La custodia en el mercado de valores. De los títulos de crédito a los valores anotados en cuenta, Santiago, Thomson Reuters, 2016.

Calderón Torres, Pablo, Mercado de capitales: una mirada retrospectiva, en Revista de Estudios Tributarios, Santiago, Centros de Estudios Tributarios, Universidad de Chile, 6, 2012.

Contreras Strauch, Osvaldo, Instituciones de derecho comercial, Santiago, LexisNexis, 2005, II.

Cortés García, Eduardo La desmaterialización de los títulos valores, Valladolid, Lex Nova, 2002.

Couyoumdian, Ricardo - Millar, René - Tocornal, Josefina, Historia de la Bolsa de 
Comercio de Santiago 1893-1993, Un siglo del mercado de valores en Chile, Editorial Universitaria, Santiago, 1993.

Couyoumdjian, Juan Ricardo, El alto comercio de Valparaiso y las grandes casas extranjeras, 1880-1930: una aproximación, en Historia, 33, Santiago, Pontificia Universidad Católica de Chile, 2000.

De Eizaguirre, José María, Derecho de los títulos-valores, Madrid, Civitas, 2003.

EsPINA, Daniel, Las anotaciones en cuenta: un nuevo medio de representación de los derechos, Madrid, Civitas, 1995.

GuZMÁN BRITo, Alejandro, La prenda sin desplazamiento de valores desmaterializados o emitidos sin impresión fisica del título que los evidencie, en Revista Chilena de Derecho, 38/1, Pontificia Universidad Católica de Chile, Santiago, 2011.

GuZmán Brito, Alejandro, El contrato de préstamo de valores, en Revista de Derecho de la Pontificia Universidad Católica de Valparaíso, 38, $1^{\mathrm{er}}$ semestre, Editorial Universitaria, Valparaíso, 2012.

Lara Aguayo, Edinson, Teoría general de los títulos valores en el derecho chileno, Santiago, LegalPublishing - Thomson Reuter, 2013.

Larroulet Vignau, Cristian - Mochón Morcillo, Francisco, Economía, 2a edición, Santiago, McGraw-Hill Interamericana, 2003.

Mankiw, George, Principios de economía, México, Cengage, 2009.

MarX, Karl, El capital. Critica a la economía política, edición de México, Fondo de Cultura Económica, 1966, III.

Morales Barría, Fernando, Prenda de valores mobiliarios a favor de los bancos, Memoria de prueba, Universidad Católica de Chile, Santiago, 1964.

RiPERT, Georges, Traité élémentaire de droit commercial, 6a édition, Paris, Librairie Générale de Droit et de Jurisprudence, 1968.

RIPERT, Georges, Traité élémentaire de droit commercial, 6a édition, Paris, Librairie Générale de Droit et de Jurisprudence, 1970, II.

Sandoval López, Ricardo, Derecho comercial, 7a edición, Santiago, Editorial Jurídica de Chile, 2007, I/1.

Samuelson, Paul - Nordhaus, William, Economía, traducción de Esther Tabasco y Luis Toharía, McGraw Hill, 2002.

VÁsquez Méndez, Guillermo, Tratado sobre el cheque. Historia, legislación, doctrina y jurisprudencia, Santiago, Editorial Jurídica de Chile, 2000.

Touzaud, Daniel, Des effets de commerce. Étude de legislation comparée, Paris, L. Larose - Forcel, 1882.

Ubilla Grandi, Luis, Teoría general de la letra de cambio y pagaré en la Ley 18.092, Santiago, Editorial Jurídica de Chile, 1990.

Tavares, María - Mello Belluzo, Luiz, Capital financiero y empresa multinacional, en Estévez, Jaime - LichtenszTejn, Samuel (compiladores), Nueva fase del capital financiero. Elementos teóricos y experiencias en América Latina, México, Nueva Imagen, 1981. 
